\title{
Cephalopod Diseases Caused by Fungi and Labyrinthulomycetes
}

\author{
Jane L. Polglase
}

\begin{abstract}
This chapter describes infections of cephalopods by both the Labyrinthulomycetes (formerly fungi, now protists) and organisms still classified as fungi, with information on how to diagnose them. Both types of infection are rare, but those by Labyrinthulomycetes in captive cephalopod populations can increase with time and may last for three or more years, raising concerns about such ubiquitous organisms for cephalopod culture.
\end{abstract}

\section{Keywords}

Cephalopod diseases - Infection • Fungi • Labyrinthulomycetes • Labyrinthulomycota • Thraustochytrids • Aplanochytrids $\bullet$ Labyrinthula

\subsection{Introduction}

As well as considering the rare cephalopod infections by organisms currently recognised as being within the fungal kingdom, this chapter covers diseases caused by organisms known most commonly as Labyrinthulomycetes. As their name suggests, the Labyrinthulomycetes were originally thought to be fungi. However, these single-celled organisms, with unique "ectoplasmic nets", are now classified as protists. Bennet et al (2017) provide the most comprehensive, recent description of the group, while Moss (1986, Chap. 11) provides excellent images of diagnostic features of these organisms.

Labyrinthulomycetes are most commonly found as marine decomposers or remineralisers of complex organic material, but can be symbionts, parasites or pathogens. There are three major groupings within the Labyrinthulomycetes: the thraustochytrids and aplanochytrids (regularly found as opportunist pathogens or parasites of invertebrates, most

J. L. Polglase ( $₫)$

Institute of Life and Earth Sciences, School of Energy,

Geoscience, Infrastructure and Society, Heriot Watt University,

Riccarton, Edinburgh, EH11 1QH, Scotland, UK

e-mail: JP44@hw.ac.uk commonly molluscs) and the labyrinthulids (not considered here but also opportunist pathogens of marine grasses and in land grasses in saline soils). The common factor that allows the Labyrinthulomycetes to become pathogenic is stress in the host.

\subsection{Thraustochytrid/Aplanochytrid Infections in Cephalopods}

In molluscs, thraustochytrids proper and aplanochytrids (collectively referred to here as thraustochytrids) are found as important pathogens or parasites of bivalves and also of nudibranchs (McLean and Porter 1982), octopus and squid.

Only one thraustochytrid infection has been described to date in European cephalopods. This was a fatal, progressive, ulcerative dermal necrosis of lesser or curled octopus, Eledone cirrhosa (Polglase 1980, 1981) found on the east coast of Scotland. The disease (originally spread from one individual) infected an entire research aquarium, despite stringent efforts to remove it, for over four years, during which a small number of other infected animals were also brought in from the wild. A similar condition had also been observed sporadically in the 1970 s/80s in Octopus vulgaris, at the Stazione Zoologica, Naples, Italy (J. B. Messenger, pers. comm. to Polglase). 


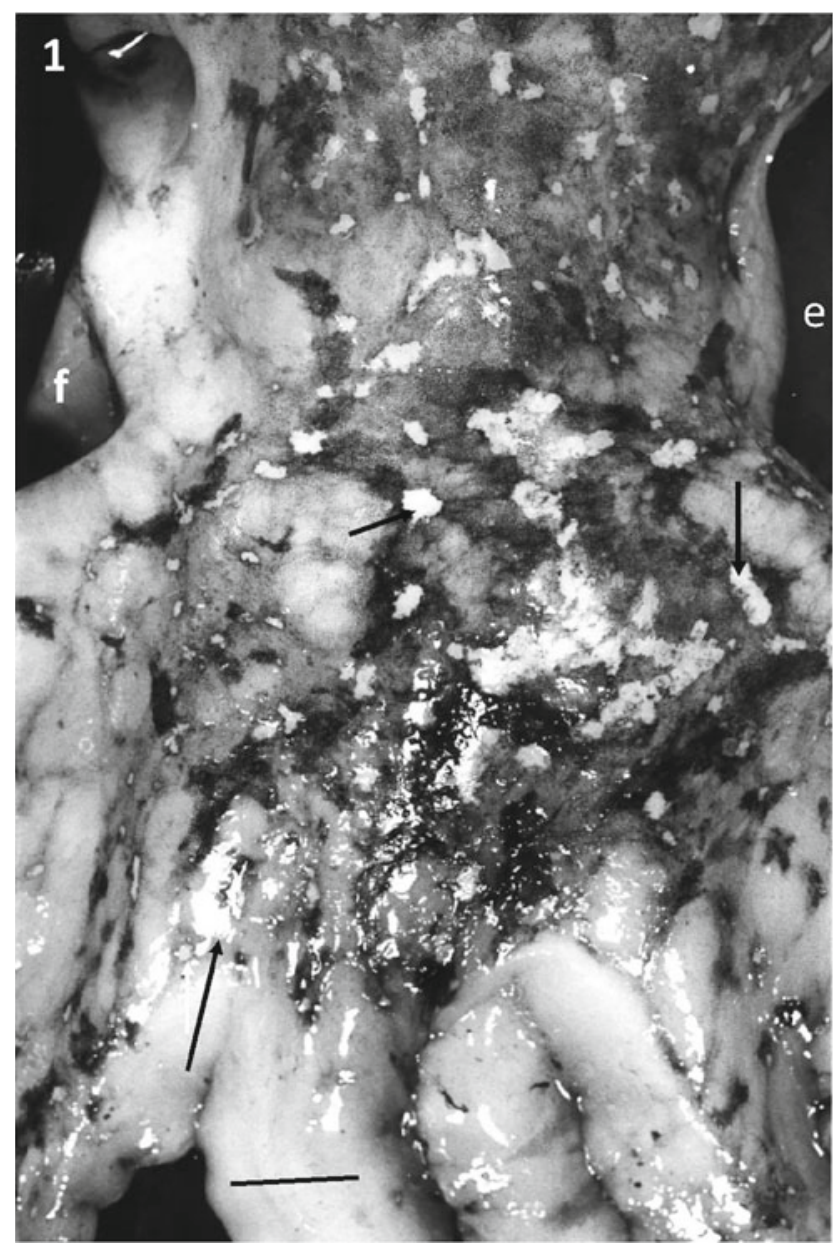

Fig. 6.1 Eledone cirrhosa showing symptoms of a rapidly progressing multi-lesion thraustochytrid infection. Arrows indicate lesions; e = eye $\mathrm{f}=$ funnel. Scale bar: $12 \mathrm{~mm}$

Key signs were patches of inactive chromatophores, from which the epidermis was then lost (Fig. 6.1). Affected animals constantly rubbed their skin and shook their arms, as if itching. The lesions deepened, multiplied and spread, either rapidly or more slowly in individuals with fewer lesions, revealing the unpigmented connective tissue and muscle layers below (Fig. 6.2). The cause of the death was not clear but could have been metabolite imbalance (see Polglase 1980). In the light microscope, clear zones of tissue destruction were seen in the lesions around rounded cells approximately $6 \mu \mathrm{m}$ in diameter (Figs. 6.3 and 6.4). The cells divided to produce diads, triads, tetrads and larger cell clusters, which point to thraustochytrid involvement (Figs. 6.3 and 6.4).

Only one organism was consistently seen in histological and electron microscope sections from all infected animals. This was a thraustochytrid tentatively identified from its life history in culture as Ulkenia amoeboidea, but more recent current work indicates that is a novel species and genus, with some metabolic differences from other thraustochytrids. In severe infections, small numbers of thraustochytrids were

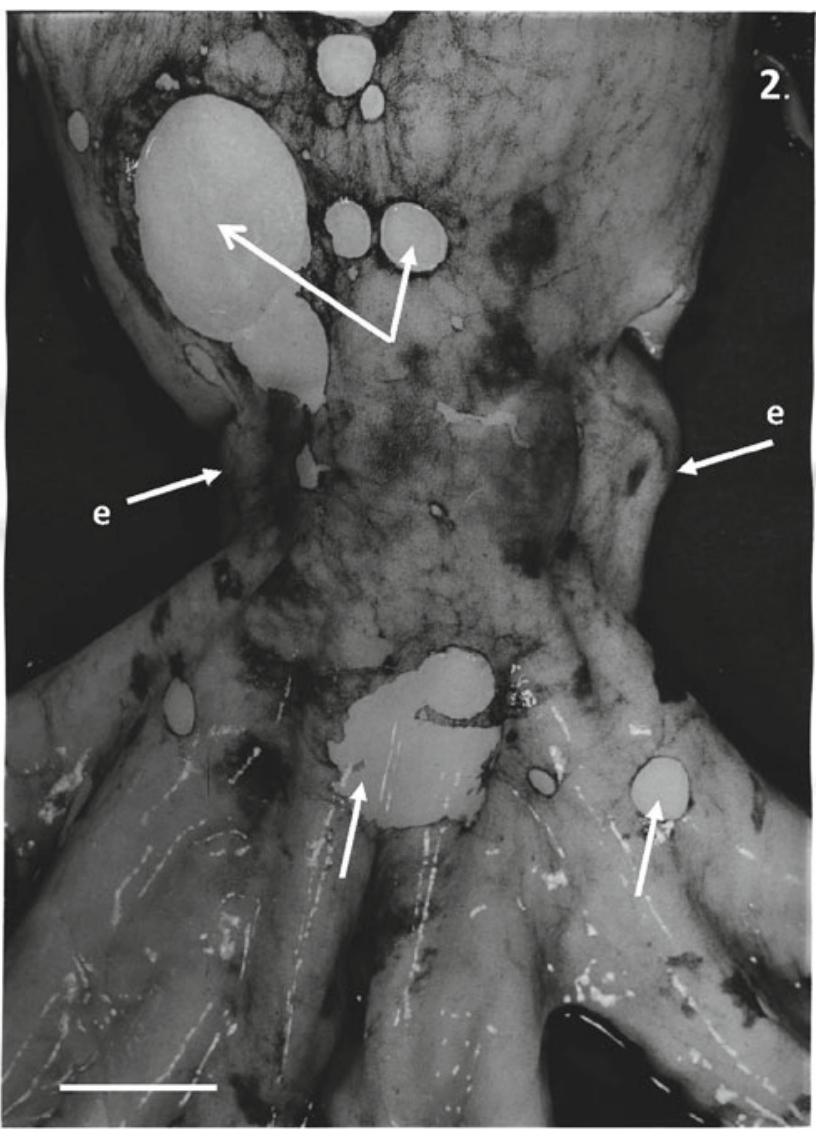

Fig. 6.2 Moribund Eledone cirrhosa, showing final stages of slow-progressing Labyrinthulomycete infection with major dermal lesions. Arrows indicate lesions; e = eye; $\mathrm{f}=$ funnel. Scale bar: $20 \mathrm{~mm}$

also seen in the gills and eyes (producing a cataract-like appearance) and in the lower dermis, but there was no evidence of a stage of systemic infection. Interestingly, labyrinthulids were also isolated from some of the lesions, but they appeared to be secondary to the thraustochytrid. Electron microscopy confirmed the diagnostic features of a thraustochytrid (see Fig. 6.8), but it was not possible to re-infect from cultures derived from the lesions.

Many haemocytes of infected animals responded by adopting the elongate "prefibroblast" morphology, seen in haemocytes moving towards the surface of mechanical wounds (Polglase et al. 1984). Groups of haemocytes were seen to produce incomplete capsules on the edge of the necrotic zones around the protists, but the thraustochytrids were never completely encapsulated and no dermal plug was ever formed across the lesion.

The condition appeared to be highly contagious (Polglase 1980) and made it extremely difficult to keep the Eledone in the aquarium for research purposes.

The only thraustochytrid infection in squid was found in the Northwest Atlantic. This is the gill disease in captive 


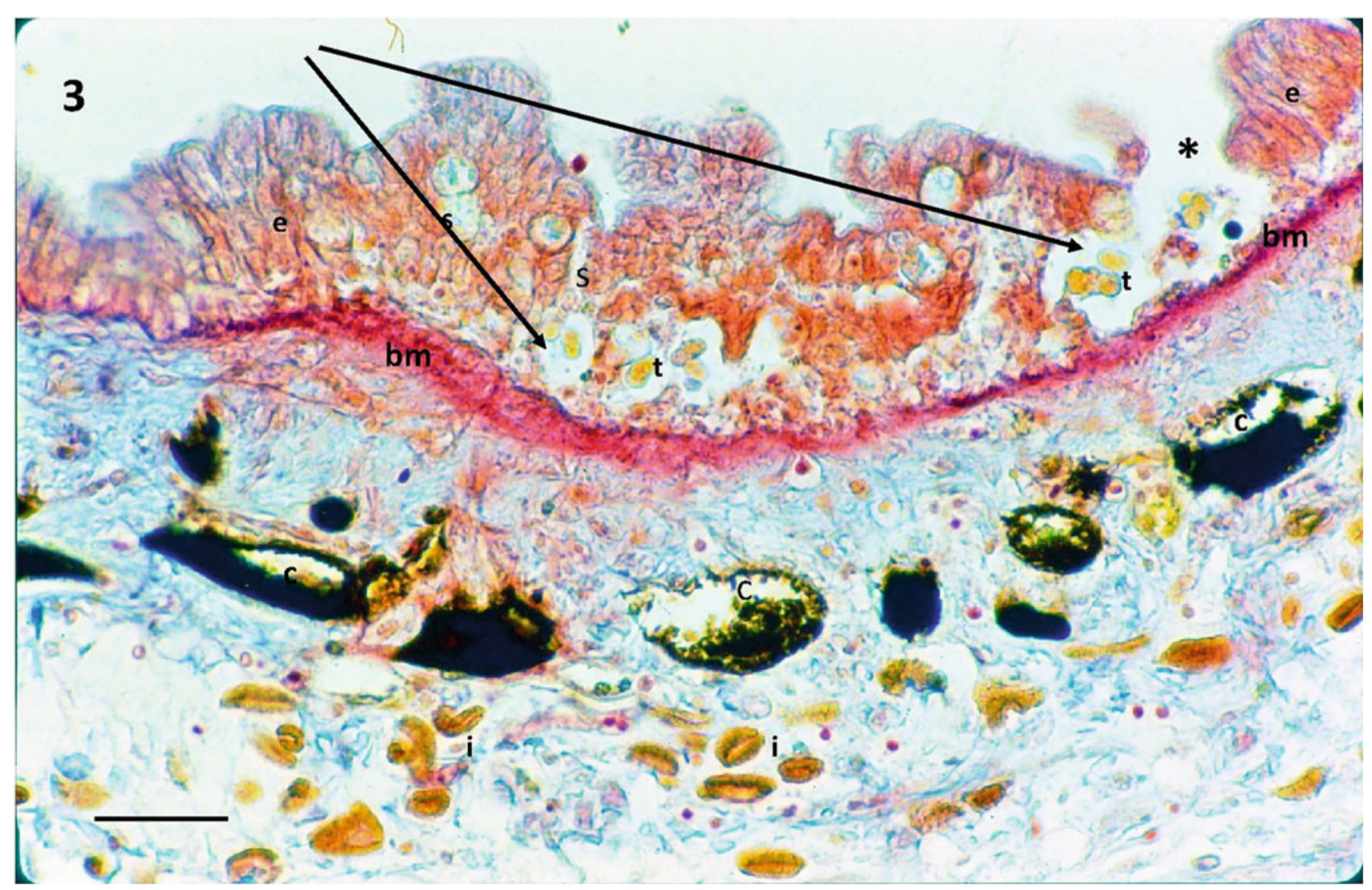

Fig. 6.3 Mallory's triple stained light microscope section showing thraustochytrids in the epidermis of Eledone cirrhosa. Arrows show clear zones where the host tissue has been dissolved by the lytic enzymes of the ectoplasmic net causing the cells to separate initially

short-finned squids, Illex illecebrosus, reported by Jones (1981) and Jones and O’Dor (1983).

In 1977-79, this disease affected squid kept in a facility at Dalhousie University, Canada, designed to produce the best conditions possible for research on these delicate animals (the Aquatron). In 1977-78, only two or three animals died, atypically, before mating, while the others remained healthy. Those that died (Jones and O'Dor 1983) had a large number of small $(1.5 \mathrm{~mm})$ white nodule-like lesions in their gills (Figs. 6.5 and 6.6) and, in the later stages of heavy infections, also on the inside of the mantle; "sufficient numbers for these to be considered a likely cause of death" (Fig. 6.6). By the end of the 1979 squid "season", however, the lesions had become the main cause of mortality. They were never observed in animals in the wild and appeared after the animals had been kept for 3 weeks or longer in the Aquatron.

Light and electron microscopy again showed that only a single organism (spherical cells about $7 \mu \mathrm{m}$ in diameter) could be identified in the lesions, often in large numbers from the basal membrane (bm) and then be lost (asterisk). $\mathrm{c}=$ chromatophore; $\quad \mathrm{e}=$ epidermis; $\mathrm{i}=$ iridophore; $\mathrm{t}=$ thraustochytrid. Scale bar: $40 \mu \mathrm{m}$

(Fig. 6.7). Ultrastructural and semi-thin sections confirmed the organism was a thraustochytrid. In semi-thin sections, diads, triads and tetrads of cells could be seen beneath the gill epithelium, with evidence of substantial tissue damage from the activities of the lytic enzymes from the ectoplasmic net but not close to the cell bodies. In advanced infections, just as in E. cirrhosa, the overlying epithelium was disrupted, releasing the thraustochytrids into the mantle cavity.

Although some cells thought to be squid amoebocytes were found close to or even partially enclosing the thraustochytrids, there were no instances of complete encirclement or any degeneration of the thraustochytrids within the lesions. Jones and O'Dor were not able to isolate the thraustochytrid into pure culture for identification but speculated that it was a species of Schizochytrium. Lack of pure cultures also meant that re-infection experiments could not be undertaken, so there is no final proof that this was a pathogen. 
Fig. 6.4 Section of Eledone cirrhosa skin from which the epidermis has been lost, allowing the thraustochytrid (t) to move down into the dermal layer. Arrows indicate areas where tissue lysis is occurring surround the dividing thraustochytrid; $\mathrm{c}=$ chromatophore,

$\mathrm{CL}=$ opportunist ciliate. Scale bar: $12 \mu \mathrm{m}$

Fig. 6.5 Female northern short-finned squid, Illex illecebrosus, ventral dissection. Gills show small white lesions typical of the thraustochytrid disease. Scale bar $\approx 40 \mathrm{~mm}$ (Courtesy of Jones and O'Dor)
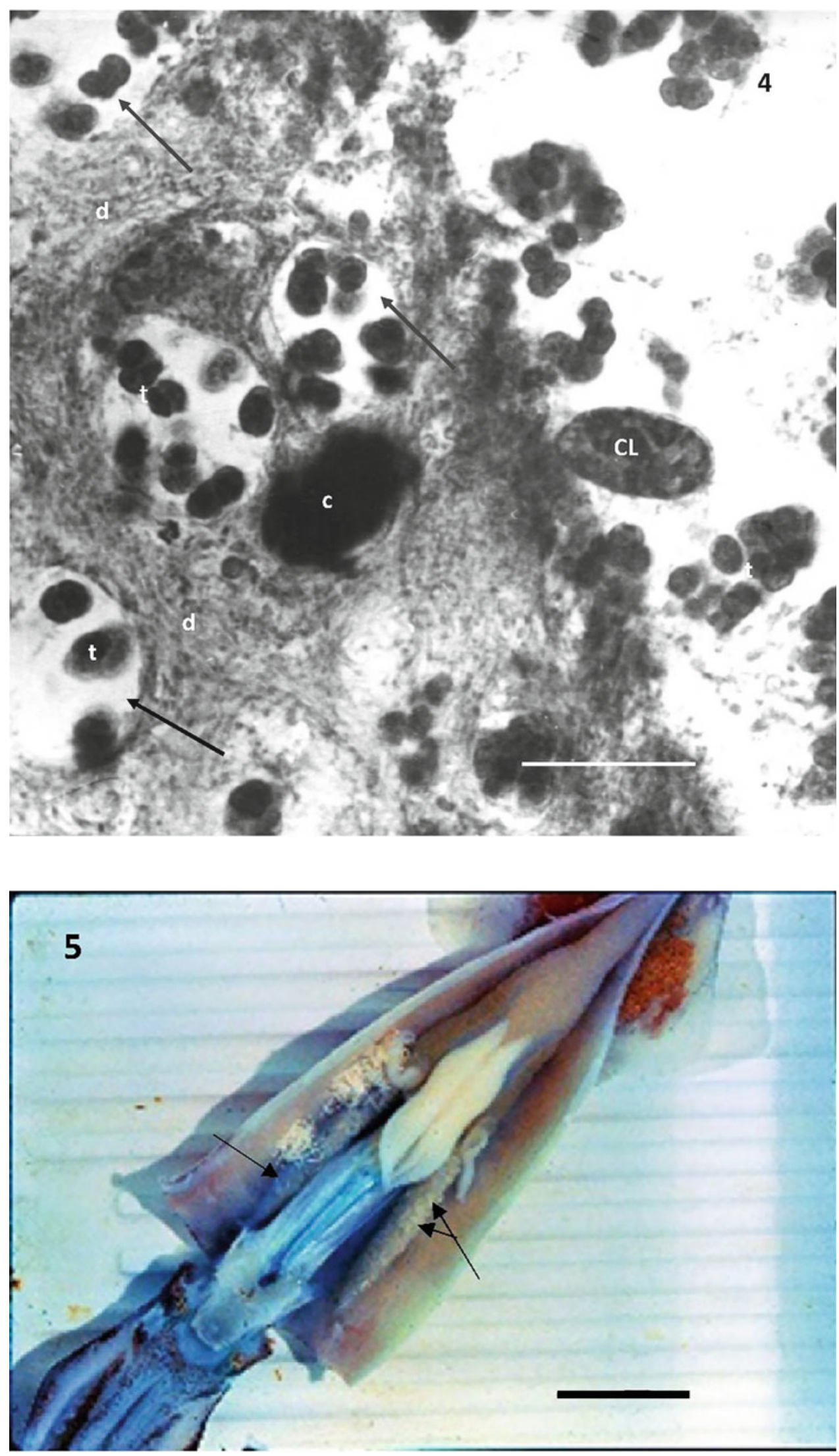


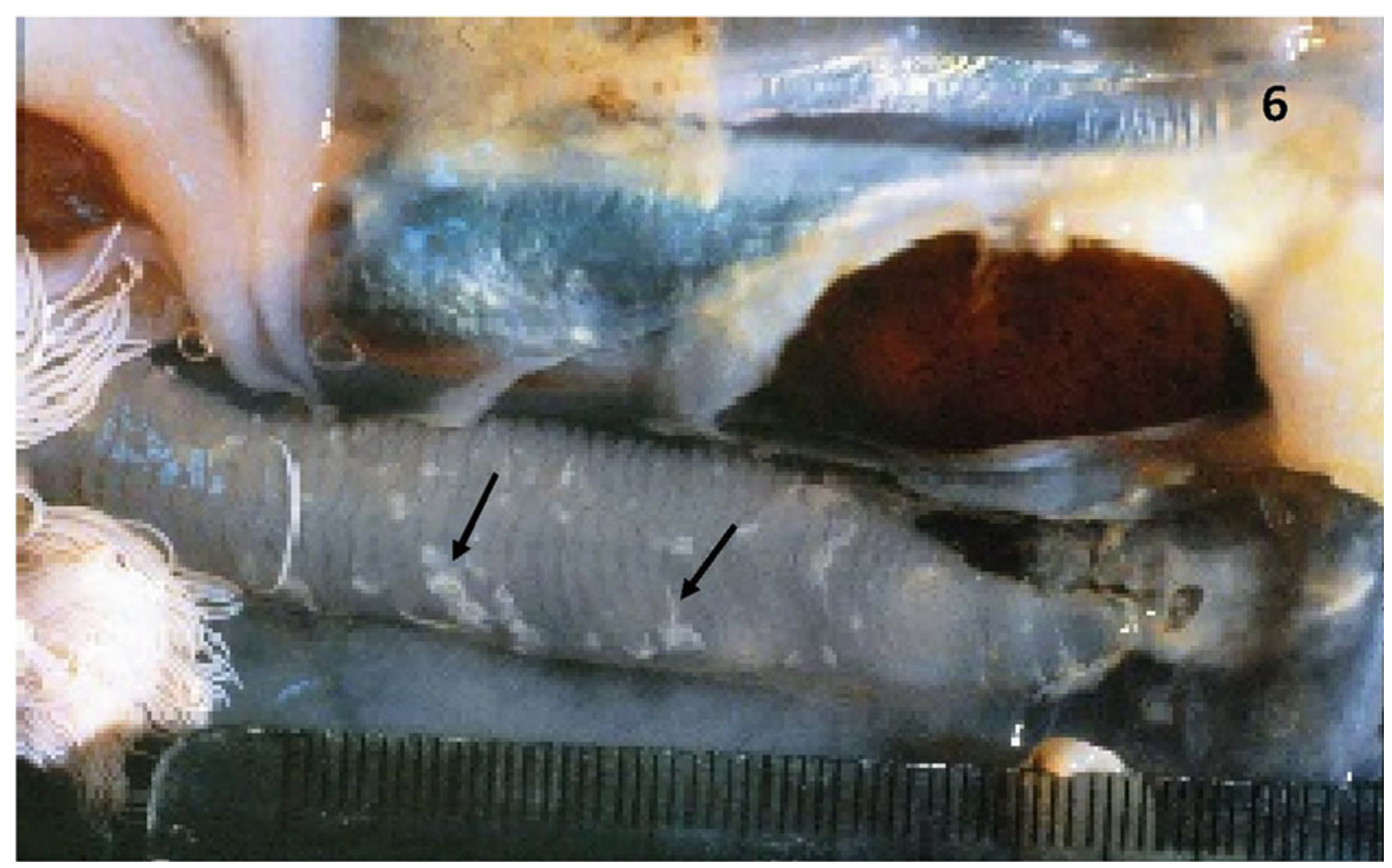

Fig. 6.6 Illex illecebrosus gill with scattered white lesions on filaments. Scale shows mm (Courtesy of Jones and O’Dor)

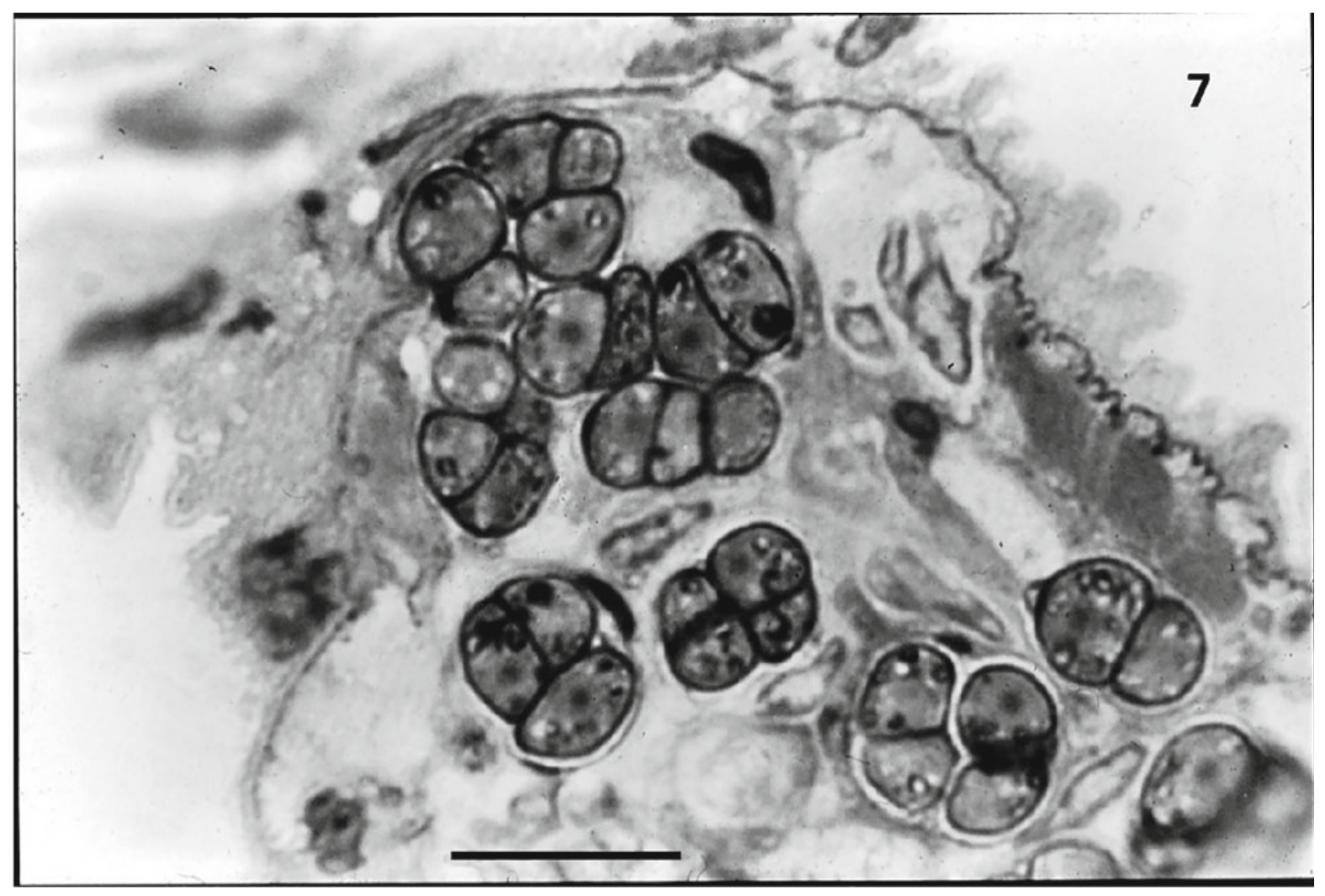

Fig. 6.7 Thraustochytrids within a lesion in the gill of Illex illecebrosus, note cells dividing to form diads, triads and tetrads. Scale bar $\approx 30 \mu \mathrm{m}$ (Courtesy of Jones and O'Dor) 


\subsection{Diagnosing a Labyrinthulomycete Infection Using Electron and Light Microscopy}

Almost all Labyrinthulomycetes have three unique, diagnostic features (see Bennett et al. (2017) and Moss (1986) for detailed descriptions). Electron microscopy shows all three, but high powered light microscopy generally reveals the ectoplasmic net and its effects.

- Unique, subcellular organelles, called sagenogenetosomes. These have been compared to spider spinnerets and secrete the ectoplasmic net system. They are positioned at the point at which the ectoplasmic net leaves the cell body and vary in structure between species. In all cases, however, ectoplasmic reticulum converges to become a dense array, which may have the appearance of a plug at the "top" of the net (Fig. 6.8).

- An ectoplasmic net. This consists only of unit membrane, continuous with that of the sagenogenetosome. It contains no organelles, only occasionally a few membranous structures. In thraustochytrids and aplanochytrids, the net takes the form of a root-like system and is known to secrete both digestive enzymes and transport nutrients
Fig. 6.8 Transmission electron micrograph of the thraustochytrid from Eledone cirrhosa, showing the sagenogenetosome (s); cell wall with layers of scales (w); the ectoplasmic net (e); $\mathrm{n}=$ nucleus; $\mathrm{g}=$ golgi; $\mathrm{m}=$ mitochondria with tubular cristae. Scale bar: $1.75 \mu \mathrm{m}$

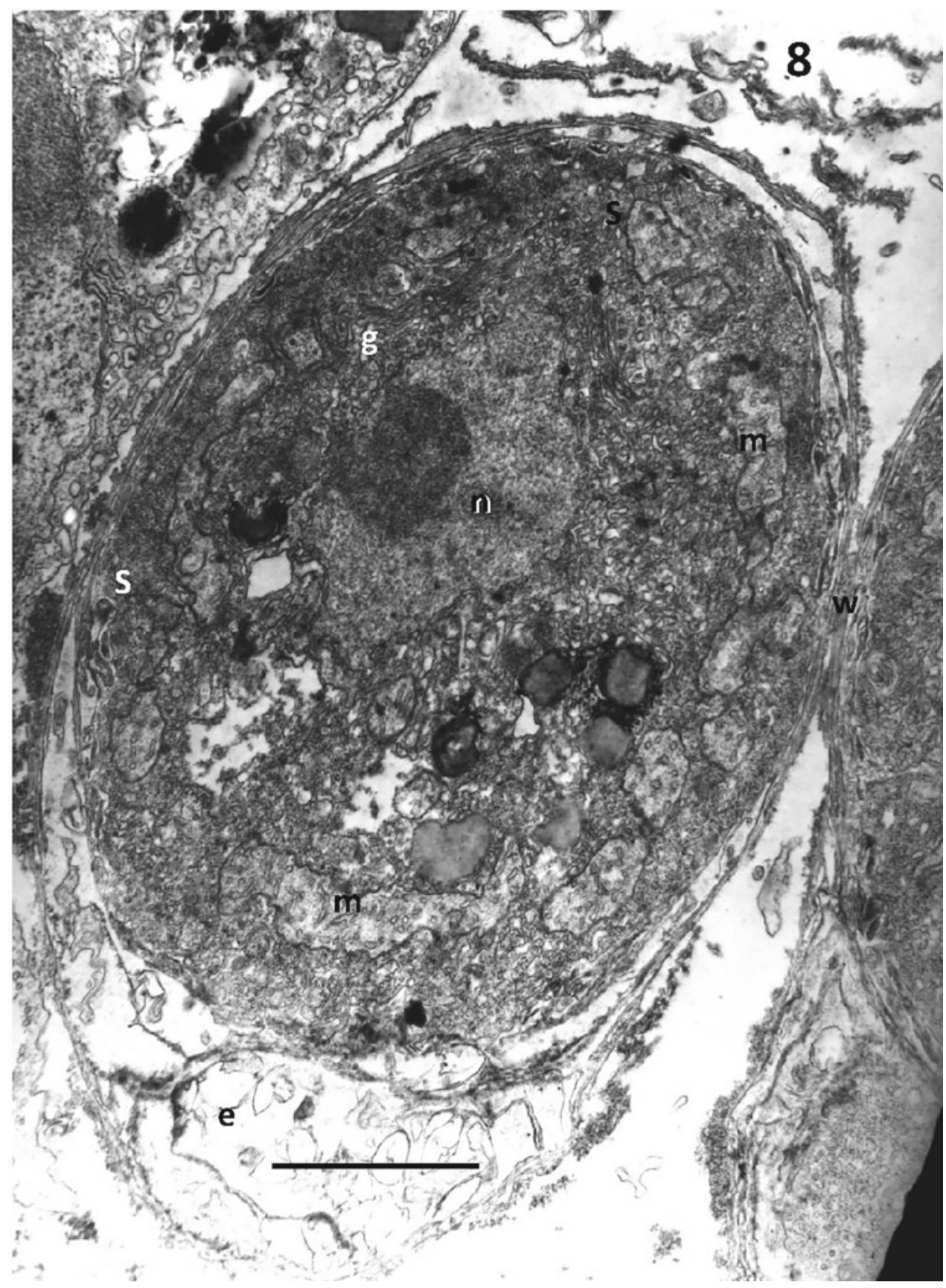


back to the cell body. The net is also known to contain actin and myosin (Preston and King 2005), and in aplanochytrids, this allows the cells to move with a crawling motion, when observed by light microscope.

- The cell wall of the Labyrinthulomycetes (Moss 1986) consists of a unit membrane over which circular scales, $2-3 \mathrm{~nm}$ thick, are laid in layers in varying numbers, depending on the species and age of the cell. These scales are made either of fucose or galactose, again dependent on species (Honda et al. 1999).

Other features of Labyrinthulomycetes useful for diagnosis are the production of biflagellated zoospores, easily seen in culture. These are not always produced, but where they are, they swim with a "flipping" motion and have an anterior flagellum, which is covered with brush-like mastigonemes, and a posterior, shorter, "whiplash" flagellum (Moss 1986, Chap. 11). Thraustochytrids and aplanochytrids are, however, extremely plastic in the life stages they can present under different nutrient and environmental conditions (Fossier Marchan et al. 2018). It is therefore essential to sequence to identify to genus and species level. Mo et al. (2002) provide a comprehensive methodology, with details of appropriate primers.

\subsection{Implications of Labyrinthulomycete Infections for Cephalopod Production}

In the E. cirrhosa infection, one infected individual infected an entire aquarium, because of its reliance on brick-lined tanks. In both cases, the infection carried over from one year to the next and increased with severity with time. Treatments for thraustochytrid infections have only been tried with bivalves with limited success, with heat shock for QPX disease in hard clams being the most successful (Dahl et al. 2011). These observations are an indication that thraustochytrids could be a major, long-lasting problem in cephalopod rearing facilities, if the animals are stressed or mechanically damaged.

\subsection{Infections Caused by Organisms Still Classified as Fungi}

Only five infections of cephalopods by organisms classified as fungi have been observed to date. The same fungus is responsible for two infections, one in an octopus and one in squid. This is the deuteromycete, Cladosporium sphaerospermum. Cladosporium is a ubiquitous, salt-tolerant, generally saprobic fungus, which has a range of beneficial and deleterious habits (Bensch et al. 2012). It was first found as an opportunist infection of a mechanical wound in an aquarium kept lesser octopus, E. cirrhosa (Polglase et al. 1984), (Figs. 6.9 and 6.10), but these authors reported that it could be cultured on agar plates and would re-infect wounds (Fig. 6.11). Almost complete healing of the original wound was observed, except where fungal hyphae ran though the dermal connective tissue out to the exterior. No marked necrosis or oedema was associated with the hyphae (pics), but the connective tissue stained less deeply and had an attenuated appearance. Increased numbers of rounded haemocytes were present, but no encapsulation of the hyphae was observed.
Fig. 6.9 Eledone cirrhosa; skin wound (w) infected with Cladosporium sphaerospermum. Arrows indicate transparent mycelium. Scale bar: $100 \mu \mathrm{m}$

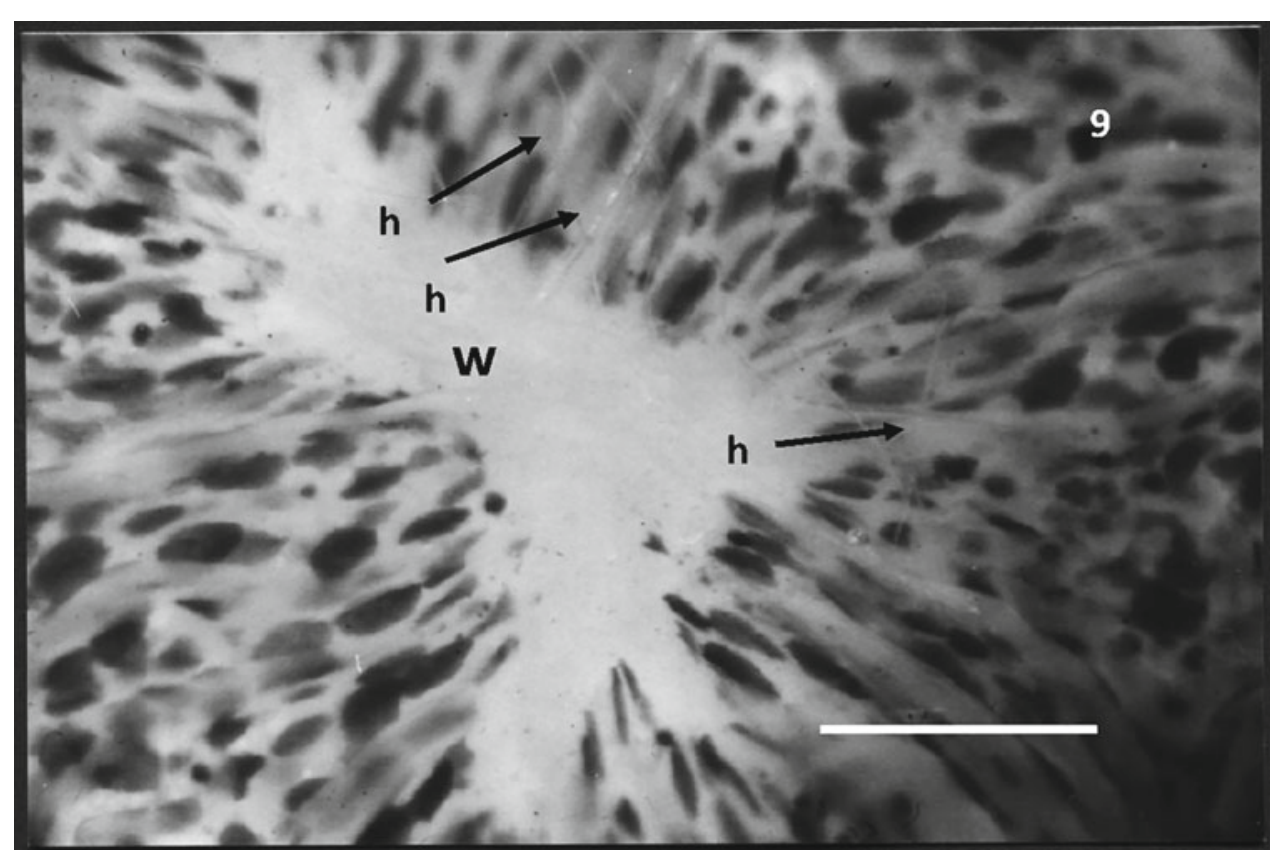


Fig. 6.10 Cladosporium

sphaerospermum mycelium

growing from dermis of a wound

in Eledone cirrhosa,

$\mathrm{c}=$ chromatophores.

Scale bar: $25 \mu \mathrm{m}$

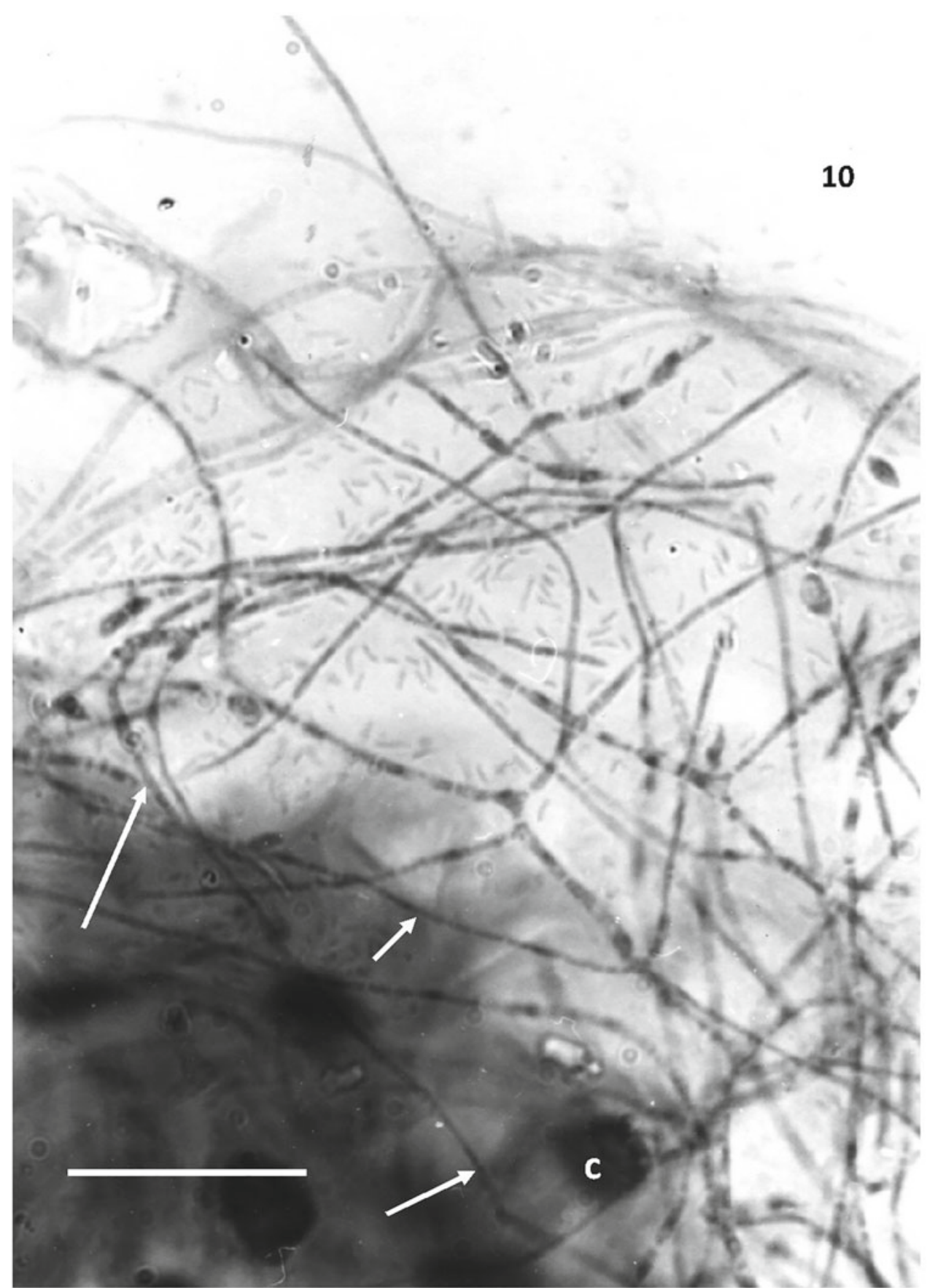




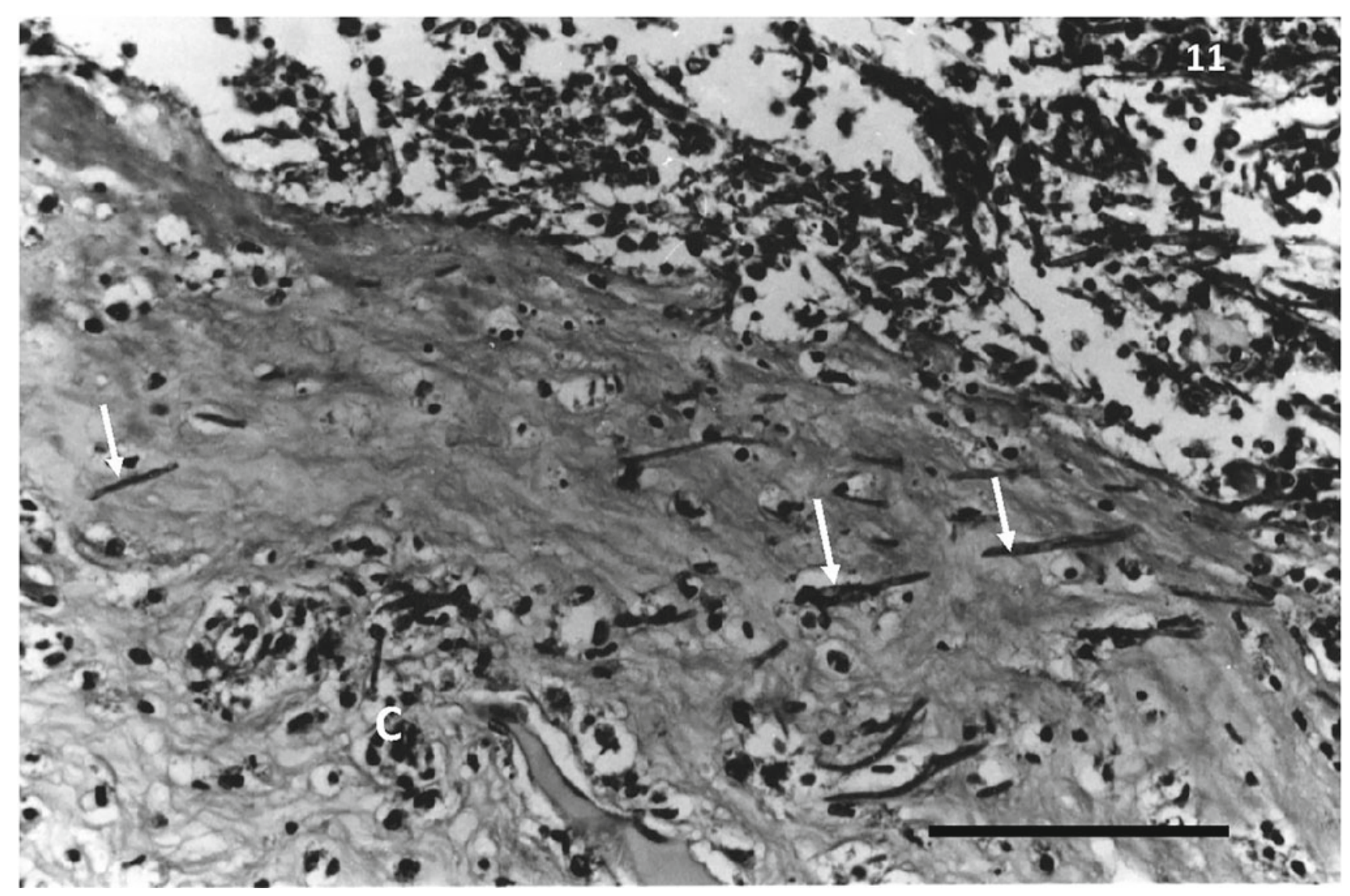

Fig. 6.11 Hyphae (arrowed) of Cladosporium sphaerospermum growing back into Eledone cirrhosa dermis after re-inoculation. Arrows indicate hyphae. $\mathrm{c}=$ chromatophore. Scale bar: $50 \mu \mathrm{m}$

Harms et al. (2006) reported a case in which a European cuttlefish, Sepia officinalis, developed an eruptive skin lesion of the dorsal mantle, which biopsy and subsequent culture revealed contained haemocyte granulomas, again induced by a Cladosporium sp. infection. The lesion was successfully treated by excision under anaesthesia, but the animal died two months later and was found to have a multi-systemic fungal infection.

Scimeca (1994) provides a previously unpublished, brief report of a Fusarium infection of the mantle of a nautilus. The fungus was identified using an indirect fluorescent antibody test for hyphae of the Fusarium group. In this case, the hyphae extended from the deep ulcer, which was the focus of the investigation, into the musculature of the mantle.

Finally, Scimeca and Oestmann (1995) mention a fungal infection, presumably therefore by a mycelial organism, in the hood of Nautilus pompilius. The abstract of this conference presentation does not give any further details.

\subsection{Concluding Remarks}

All these infections, both by the Labyrinthulomycetes and organisms still classified as fungi, have been reported in captive animals, so stress and/or mechanical damage from handling are again likely to have been contributory factors, allowing the infections to establish and develop. There are, however, still very small numbers of these reports and none to date of true fungal infections in cephalopods from the wild raising the question, "What is it about cephalopods that keeps them free from attack by the fungi commonly found in the sea, which infect other invertebrates and vertebrates to a much higher degree?".

Acknowledgements Jane Polglase thanks Dr. Gwyneth M. Jones, Seatech Ltd., Halifax, Nova Scotia, Canada, and Dr. Ronald O'Dor, Dalhousie University, Halifax, Nova Scotia, Canada, for kind permission to reproduce their images. 


\section{References}

Bennett RM, Honda D, Beakes GW, Thines M (2017) Labyrinthulomycota. In: Archibald J, Simpson A, Slamovits C (eds) Handbook of the protists. Springer, Cham, Switzerland, pp 507-542

Bensch K, Braun U, Graenewald JZ, Crous PW (2012) The genus Cladosporium. Stud Mycol 72(1):1-401

Dahl SF, Perrigault M, Liu Q, Collier JL, Barnes DA, Allam D (2011) Effects of temperature on hard clam (Mercenaria mercenaria) immunity and QPX (Quahog Parasite Unknown) disease development: I. Dynamics of QPX disease. J Invert Pathol 106(2):314-321

Fossier Marchan L, Lee Chang KJ, Nichols PD, Mitchell WJ, Polglas JL, Gutierrez JT (2018) Taxonomy, ecology and biotechnological applications of thraustochytrids: a review. Biotech Adv 36(1):26-46

Harms CA, Lewbart GA, McAlarney R, Christian LS, Geissler KA, Lemons C (2006) Surgical excision of mycotic (Cladosporium sp.) granulomas from the mantle of a cuttlefish (Sepia officinalis). J Zoo Wildlife Med 37(4):524-530

Honda D, Yokochi T, Nakahara T, Raghukumar S, Nakagiri A, Schaumann K, Nigashihara T (1999) Molecular phylogeny of labyrinthulids and thraustochytrids based on the sequencing of the 18 S ribosomal RNA gene. J Eukaryot Microbiol 46(6):637-647

Jones G (1981) Thraustochytrid pathogens. Bull Brit Mycol Soc 16 (suppl 1):5-6

Jones G, O'Dor RK (1983) Ultrastructural observations on a thraustochytrid fungus parasitic on the gills of squid (Ilex illecebrosus Lesueur). J Parasitol 69: 903-911

McLean N, Porter D (1982) Yellow spot disease of Tritonea diomedea Bergh (Mollusca: Gastropoda: Nudibranchia): encapsulation of the thraustochytriaceous parasite by host amoebocytes. J Parasitol 68:243-252

Mo C, Douek J, Rinkevich B (2002) Development of a PCR strategy for thraustochytrid identification based on $18 \mathrm{~S}$ rDNA sequences. Mar Biol 140:883-889

Moss ST (1986) Biology and phylogeny of the labyrinthulales and thraustochytriales. In: Moss ST (ed) The biology of the marine fungi. Cambridge University Press, Cambridge, pp 105-130

Polglase JL (1980) A preliminary report on the thraustochytrid(s) and labyrinthulid(s) associated with a pathological condition in the lesser octopus, Eledone cirrhosa. Bot Mar 23:699-706

Polglase JL (1981) Thraustochytrids as potential pathogens of marine animals. Abstract published in Bull Br Mycol Soc 16(suppl 1):5 (Full manuscript now available on Research gate)

Polglase JL, Dix NJ, Bullock AM (1984) Infection of skin wounds in the lesser octopus, Eledone cirrhosa, by Cladosporium sphaerospermum. Trans Brit Mycol Soc 82:577-580

Preston TM, King CA (2005) Actin-based motility in the net slime mould Labyrinthula: evidence for the role of myosin in gliding movement. J Eukaryot Microbiol 52(6):461-475

Scimeca JM (1994) The cephalopods in invertebrate medicine (2nd edn). Wiley, pp 112-125

Scimeca JM, Oestmann D (1995) Selected diseases of captive and laboratory-reared cephalopods. Poster presented to a meeting of the International Association for Aquat Ani Med 26:79. Recorded in online proceedings at https://www.vin.com/apputil/content/ defaultadv1.aspx id=3977208\&pid=11257\&
Open Access This chapter is licensed under the terms of the Creative Commons Attribution 4.0 International License (http://creative commons.org/licenses/by/4.0/), which permits use, sharing, adaptation, distribution and reproduction in any medium or format, as long as you give appropriate credit to the original author(s) and the source, provide a link to the Creative Commons licence and indicate if changes were made.
The images or other third party material in this chapter are included in the chapter's Creative Commons licence, unless indicated otherwise in a credit line to the material. If material is not included in the chapter's Creative Commons licence and your intended use is not permitted by statutory regulation or exceeds the permitted use, you will need to obtain permission directly from the copyright holder. 